\title{
Effects of credit market freedom on the convergence of Chinese banks' profits
}

\begin{abstract}
Using an unbalanced panel of 96 banks that operate in the Chinese banking sector from 2007 to 2014, we first seek to uncover the relation between credit market freedom and bank profit. Thereafter, we further analyse the freedom effects on the convergence of bank profit so as to explain the prevailing persistent fall in the profit growth of Chinese banks. Two types of convergence are considered in this study: beta-convergence and sigma-convergence, which are estimated by using dynamic panel data estimator. Our results suggest that betaconvergence does not take place for all ownership structures until discrepancies on their traits and structural parameters are conditioned out, suggesting that it is the conditional betaconvergence rather than the absolute beta-convergence that transpires in China's banking sector. While freedom is found to reduce profit growth significantly, its negative impact on the speed of beta-convergence is arguably negligible. This alludes that China has done reasonably well in balancing its liberalization initiatives with stabilization measures so that the fall in profits instigated by freedom does not significantly overshoot its long-run equilibrium path. Credit market freedom is also found to be a significant catalyst for sigmaconvergence for all ownership structures but state-owned commercial banks and foreign banks.
\end{abstract}

Keyword: Economic freedom; Beta-convergence; Sigma-convergence; System GMM 